\title{
The Clustering and Sorting in the Programme Management
}

\author{
NIU Bo ${ }^{1, a}$, LI Hui-min ${ }^{2, b}$ \\ ${ }^{1}$ Schools of Civil Engineering, Xi'an University of Architecture and Technology, P.R. China 71005 \\ 5 \\ ${ }^{2}$ Schools of Civil Engineering, Xi'an University of Architecture and Technology, P.R. China 71005 \\ 5 \\ anb198069@126.com, ${ }^{\mathrm{b}}$ li_huimin2005@126.com
}

Keywords: Programme management. Programme management office. Clustering. Sorting

\begin{abstract}
With increasing business management projects, managers find incongruities between organization as a whole and individual project which influence the achievement of overall business goals. Objectively, multiple projects of business management need to be clustered into programme for management in accordance with their own structure properties so as to conduct input and output in the form of system, to promote the orderly execution of projects and to improve the ability of organization, further achieving its objectives. Programme is not a simple clustering of projects, and between programme management and project management there are differences which are clearly reflected in the form and content of life cycle of programme. Accomplished by programme management office, programme management can be divided into controlled and coordinated types grounded in the control force of this office over programme. Despite the differences between two types of programme management offices, it is common to cluster and sort the projects in programme. In this thesis, dynamic fuzzy clustering method and AHP method are adopted to cluster projects and sort sub-programmes respectively, because dynamic clustering and sorting is an important guarantee of enhancing the effectiveness and efficiency of programme management.
\end{abstract}

\section{Introduction}

With increasing construction business scales and projects, managers find difficulties in managing. Typically, project branches try to contract businesses to achieve maximum self-interests and contend for corporate resources before and behind the scenes to ensure the success of these businesses. The result is that there are surplus resources in some branches which pay high price for success, while there is a lack of resources in other branches for which it is difficult to avoid failure despite much effort. It seems that this is just a problem of resource allocation, but in fact it reflects the management capacity of an organization in projects, that is, there is a weak management region between organization as a whole and individual project. The misconduct of individual project in this region not only destroys the overall strategic objectives of an organization but also influences the goals of other projects in it, ultimately affecting its development.

\section{Programme management}

In order to resolve the problems between the strategy of business management and the implementation of multi-project management, a variety of scholars put forward their own views, and among resolutions the most important is to add a new management link (called programme management) in both.

The concept of programme management. Ferns and Pellegrinelli thought that programme was a management framework used to organize existing projects or define new projects so as to get larger interests ${ }^{[1,2]}$. Lycett and Burke argued that projects in programme were related and that clustering of these projects was aimed at getting the interests that their single management couldn't get ${ }^{[3]}$. The definitions of Project Management Institute (PMI) and The Association of Project Management (APM) on programme are similar to those abovementioned, but the difference between them is that both institutes believed that the interests achieved in programme were strategic ${ }^{[4,5]}$. Managing successful 
programmes published by Office of Government Commerce (OGC) thought that programme included projects and some relative activities without the form of project and that the purpose of clustering projects was to achieve interests with strategic importance ${ }^{[6]}$.

While there are differences between the definitions of programme from scholars and institutes, most of them think that programme is constituted by a set of projects and that an organization can get additional interests if these projects are placed under a framework for coordinated management. Coordinating projects in the form of programme is an important function of programme management, but its function is not merely to coordinate. For example, US aerospace and national defense areas acquired, developed, maintained and increased some ability many years ago, which is called programme ${ }^{[7]}$. Project \& Program Management for Enterprise Innovation (P2M) published by Engineering Advancement Association of Japan(ENAA) indicated that programme and its management were a practical capability to cope with external environment, an ability which allows an enterprise to flexibly deal with problems with ambiguity, complexity, uncertainty and expandability ${ }^{[8]}$.

In conclusion, the internal power of implementing programme management for an enterprise is first toincrease its capabilities, and the most direct ones refer to those of ensuring its effective resource utilization, improving its production efficiency, enhancing its learning and increasing its knowledge accumulation and flow as well as those of ensuring that an enterprise copes with changes from external environmental rapidly and effectively, carries out business strategy successfully and achieves various set objectives. The method of improving capabilities is to group projects and activities related to them, to manage this group system, to completely input the projects in this system and to expect to get larger overall output. This group system refers to programme.

Different from project management, the objectives of programme management can't be often described as a deliverable product or service in the preliminary stage, but a relatively fuzzy goal or expectation which may adjust with prolongation of time and change of external environment. That is, programme often has higher fuzziness and uncertainty in the initial stage. It lasts for a longer time, but doesn't always has certain time and range which need to adjust with the change of objectives, so it has no linear life cycle, but an uncertain one. Programme consists of projects and relevant activities, and its management procedure and goal setting are associated with the environment, not always a group of universal principles and procedures. Successful programme presents as the achievement of objectives or interests an organization has set, but doesn't always manifest the success of all component elements.

Life cycle of programme. Although there are some diversities in the expression forms of life cycles of projects, these life cycles show linear mode and have relatively fixed deadline generally, which is related to the goal setting of these projects (accomplish one-time task of certain deliverable products in a fixed deadline). Nonetheless, programme is between strategic management and project management, achieves the objectives and strategies of an organization by managing multiple projects, and varies with changes of the objectives and strategies. Therefore, the life cycle of programme could be linear, but nonlinear and with rolling cyclicity in most cases. (Fig.1)

While the life cycle of programme can be divided into planning, organizing, developing and evaluating stages, its work content is largely different from project management. (Tab. 1)

\section{(1) Planning stage}

The objective and strategy setting of an organization are influenced by a variety of factors, such as stimulation of external environment, restriction of internal environment, constraint of stakeholders as well as restraints of knowledge, experience, capability and risk preference of the organization. Among various constraints and influencing factors, the organization should first correctly identify these factors and their change trends, study the strategies of action it may take, and then choose the best course of action in balancing benefits and risks. This stage refers to a process of making decisions and of describing and planning overall programme management.

(2) Organizing stage

After the objectives and strategies of an organization are determined, programme enters organizing stage in which the main task is to resolve strategic activities, group existing projects or define new projects as well as related activities on the basis of system and objectivity, and establish programme as 
a carrier of achieving objectives. No matter whether the objectives and strategies of an organization are clear enough and measurable, projects must be defined as certain deliverable products. The structure within programme should be analyzed clearly, the priority level between projects be determined, the interface between them be divided and the influencing relation between them be analyzed to conduct resource plan, making clear how to acquire and allocate resources.

(3) Developing stage

Developing stage is mainly responsible for monitoring the performance of programme and adjusting it at the right time. In order to achieve this goal, programme needs an efficient mechanism of acquiring information and support and grounded in it carries out dynamic management. Correctly dealing with relations between projects, especially various constraint relations in the performance of projects, should try to reduce the influences caused by other levels of projects for their constraints are not met or not met fully on the basis of ensuring the successful operation of high-level projects. It should be noted that the level relationship between projects is not changeless, but dynamic, a complete and overall considered result based on constant evaluation.

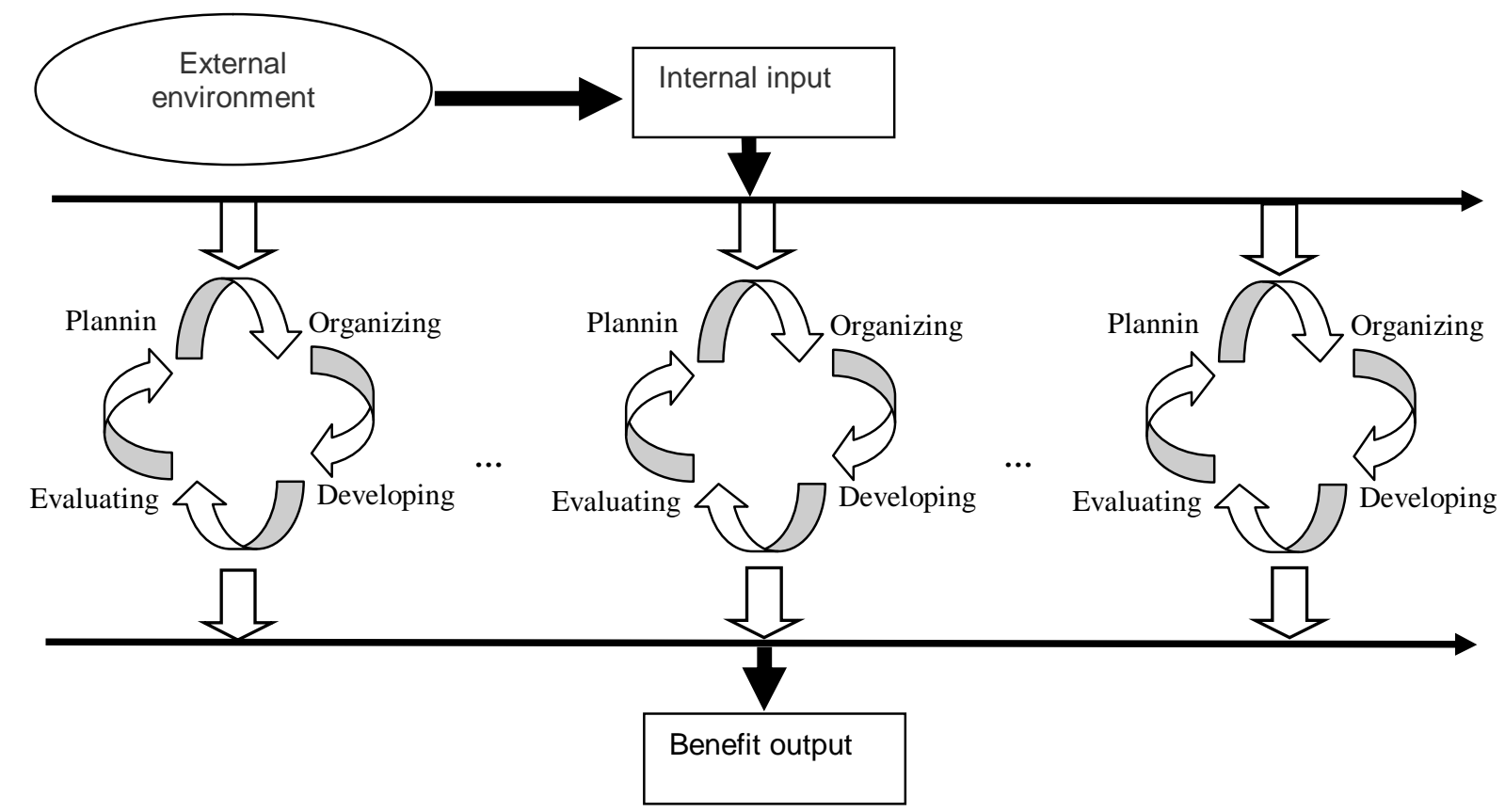

(4) Evaluating stage

Fig. 1 Life cycle of programme

During the operation of programme, evaluating stage is conducted dynamically, and its content refers to whether the external environment of implementing programme changes, whether stakeholders vary, whether the objectives and strategies of an organization need to be adjusted, whether the operation of programme are normal, whether the set expectation of interests or objectives can be achieved, whether some expectations and objectives need to be added or deleted, as well as whether the programme established grounded in this needs to be adjusted.

Programme management is aimed at enhancing an organization's capability to implement strategic objectives and achieve expected benefits, but programme in its life cycle probably varies as the organization changes its strategies and adjusts some ones under implementation with changes of environment. In fact, uncertain life cycle form of programme is an important expression of its flexibility and pertinence, and the setting of too strict life cycle form limits its adjustment capacity to cope with various changes. 
Tab.1 Life cycle of programme and main work

\begin{tabular}{|c|c|}
\hline Life cycle of programme & Main work \\
\hline Planning stage & $\begin{array}{c}\text { Environmental identity } \\
\text { Interest identity } \\
\text { Risk identity } \\
\text { Stakeholder identity } \\
\text { Strategies of action taken probably } \\
\text { Best course of action }\end{array}$ \\
\hline Organizing stage & $\begin{array}{c}\text { Formation of structure of an organization (adjustment) } \\
\text { Definition of projects } \\
\text { Determination of priority } \\
\text { Analysis on constraint relations } \\
\text { Resource plan } \\
\text { Analysis on interfaces between projects }\end{array}$ \\
\hline Developing stage & $\begin{array}{c}\text { Dynamically evaluate the work under implementation } \\
\text { Constraint of dynamic identity } \\
\text { Constraint sorting } \\
\text { Ensure the constraint of high-level projects } \\
\text { Limit influences caused by constraints }\end{array}$ \\
\hline Evaluating stage & $\begin{array}{l}\text { Evaluate expected benefits } \\
\text { Evaluate environment } \\
\text { Evaluate the interests of stakeholders } \\
\text { Evaluate the operation of programme }\end{array}$ \\
\hline
\end{tabular}

\section{Programme management office}

During the process of practice, programme management easily produces various problems related to management and thus is criticized, such as lack of effective cooperation between projects of programme, excess control over key point, absence of flexibility in changeable environment, and confusion about responsibility caused by requirements on managers. These problems make programme tend to conduct centralized management in terms of management methods. According to an investigation, $68.9 \%$ of projects in programme management are managed intensively, which shows that programme tends to intensively control projects ${ }^{[9,10]}$. The centralized management and control of programme can be dominated by a top manager, but in most cases achieved by a centralized control center. Besides, the strengths and weaknesses of centralized control often determine the difficulty degree of programme management and reflect its level.

The centralized control center of programme management is often called programme management office which is developed from project management office. Project Management Institute (2008) said that project management office refers to an organizational body or entity assigned various responsibilities related to the centralized and coordinated management of those projects under its domain. The responsibilities of the PMO can range from providing project management support functions to actually being responsible for the direct management of a project. The main functions of programme management office are similar to those of project management office, but more complex than those. From the process of management, the former ranges from strategic management to project management; from the scope of management, it not only includes project department but also involves function department related to it; from the content of management, it refers to dynamic management of multiple projects. Compared to project management office, therefore, programme management office has higher level, changeable organizational characteristics as well as more difficult management tasks and achieves various objectives.

For different enterprises, programme management offices vary in organizational forms, functions and rights, because these comprehensive factors should be considered, such as the fuzziness degree of goals and expected interests of programme that an enterprise needs to carry out, the degree that an enterprise needs to make adjustment in coping with external environmental changes, organizational level and span of an enterprise, as well as corporate management capability and culture. In general, programme management offices with different performances can be divided into coordinated and controlled offices. 


\section{(1) Coordinated programme management office}

Coordinated programme management office is mainly responsible for making programme at the beginning of definition consider the coordination of various factors, build the logical relation and interface between projects, formulate the coordination procedure for cross- projects and departments, allocate limited resources between projects and give proper resolutions in face of resource contention. During the implementation of programme, meanwhile, it provides simple, clear and timely information service for top managers within an organization as well as technical program or procedure for projects and their members.

Finally, this office provides various decisions and supports for function department, improves information gathering and flow of programme during the process of implementation, and strengthens accumulation and transmission of knowledge between projects.

(2) Controlled programme management office

Controlled programme management office is more systematic in terms of centralized control, participates in formulation of strategic plans at the beginning of programme implementation, and has an overall planning for the objectives, establishment and adjustment of programme. During the implementation of projects, this office constantly conducts dynamic management, including dynamic allocation and adjustment of resources, resolves conflicts between resources, coordinates and optimizes various relations and procedures, rapidly responds to changes of environment and strategic objectives, initiates or ends projects at the proper time, and adjusts objectives and composition of programme. At the same time, it builds a new evaluation system suitable for programme management, gives proper boost to projects and correctly evaluates implementation of projects, especially those with lower priorities, coordinated ones as well as those which suspend or end projects due to adjustment of objectives and tasks of programme. In the life cycle of programme, this office always increases the abilities of an organization, including developing new organizational culture, management standard as well as technical standard and procedure, and promotes to establish learning organization. Of course, this office provides support for shortcomings occurred in projects, such as combining the knowledge of management technique, risk management and financial management.

It can be seen that two types of programme management offices are different in management rights, contents and other aspects. The coordinated one in the same level as project and function departments little changes the existing system of an organization, but its management rights are limited, which makes it difficult to take on responsibilities for the success (or failure) of programme in dealing with some complex resource conflicts. Thus, this office is mainly suitable for some programmes with clear objectives and little adjustment of objectives and composition during implementation and whose results are easy to be evaluated. While the controlled one, whose level is higher than those of project and function departments, largely changes the original structural system of an organization, has higher management rights and is responsible for the objectives of programme. Thus, this office is mainly suitable for carrying out these programmes with fuzzy strategies, rapid environmental changes as well as more changes and adjustment during implementation, whose interests are difficult to be forecasted and which need both control and flexibility.

\section{Sub-programme clustering and sorting of programme}

During the implementation of programme management, there is often a concept that an organization should explore one standard method suitable for all projects of programme, and the essence of this concept is to limit the probable changes of programme, thus no matter how condition changes, there could be one mode corresponding to it. In fact, however, the projects of programme have non-uniformity, its objectives also vary with environmental changes and strategic adjustment, and this method of seeking fixed mode is easy to result in rigid management, excess control, slow response as well as lack of flexibility and pertinence. Therefore, dynamic management is a prominent feature of programme management, and this dynamic nature not only reflects in the process of implementation, but also appears in the processes of decision-making and planning, that is, programme could be of 
constant changes which probably come from external stimulation or from internal needs or from both. In the dynamic management of programme, there may occur various changes and adjustment, such as decomposition of strategies, definition of projects, determination of priority level and allocation of resources, and in this process it is the most common method to cluster and sort projects of programme.

Sub-programme clustering of programme. If the programme is regarded as a system which has structure, the projects of programme are gathered together in accordance with their own correlations to constitute subsystems of programme. Grounded in the theory of system science, when a system becomes increasingly complex, its complexity and accuracy will be mutually exclusive. That is, more complex the system is, lower the capability of meaningful accuracy is. In a complex large system, some factors and their changes are difficult to grasp accurately, and managers can't also investigate all factors and processes, so they can only control the main factors, neglecting less important ones. In fact, this leads to fuzziness of system objectively, so the method of fuzzy mathematics can be used to cluster projects in a system.

Clustering projects is grounded in their own characteristics, but in most cases there isn't probably a clear limit between projects. Meanwhile, there isn't always a standard mode to cluster these projects, and changes of indexes grounded are successive, so the method of fuzzy clustering is in line with objective reality. Using this method should first make clear the following relations:

(1) Fuzzy correlativity: $R$ is the matrix of fuzzy relations between every two projects of programme. If $R$ is reflexive, symmetrical and transitive, it is described as a fuzzy correlativity of $U$, namely $R$, That is, if $R$, is a fuzzy correlativity of project set $U$, any projects (including $u, v, w$ ) in the set can be met with $\forall u, v, w \in U$ :

$$
\begin{aligned}
& \text { Rol }(u, u)=1 \\
& R(v, u)=R(u, v)
\end{aligned}
$$

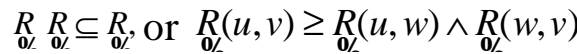

$U$ is a set of all projects in programme. In the fuzzy correlativity, from Relation(1), a project $u$ is most related to itself and the degree of its relativity is 1; from Relation(2), obviously the degree of relativity between projects $u$ and $v$ is the same as that between projects $v$ and $u$; from Relation(3), the relativity established between two projects is larger than that established between other projects.

(2) Clustering conformity relation: $R_{0}$ is a fuzzy correlativity of $U, \alpha, \beta \in[0,1]$, and if $\alpha<\beta,{ }_{\alpha}^{R}, R_{\alpha},{ }_{\beta}$ are used to work out quotient sets of $U$ respectively:

$$
\begin{aligned}
& U / R_{\text {of }}=\left\{A_{1}^{(\alpha)}, A_{2}^{(\alpha)}, \ldots, A_{m}^{(\alpha)}\right\}, \\
& U / R_{\text {o }}^{R_{R}}=\left\{A_{1}^{(\beta)}, A_{2}^{(\beta)}, \ldots, A_{n}^{(\beta)}\right\}
\end{aligned}
$$

Thus when $m \leq n$ and $A_{i}^{(\alpha)} \mid A_{j}^{(\beta)} \neq \varnothing, A_{j}^{(\beta)} \subseteq A_{i}^{(\alpha)}$.

It can be seen from this relation that when $\alpha$-cut set of fuzzy correlativity ${ }_{0}^{R}$ of project set $U$ is used to divide $U$ and the value of $\alpha$ is lower, the number of sub-programme is less, and vice versa. It should be noted that the division of category is transformed to subdivision based on original clustering with the improvement of $\alpha$ level and the projects originally belonging to some subcategory cannot enter other categories, reflecting the uniformity of project division in clustering.

By synthesizing the two relations above and basic theory of fuzzy mathematics, the steps of analyzing dynamic clustering of fuzzy correlativity ${ }_{0}^{R}, 0$ p programme set $U$ are as follows:

(1)Inspect the reflexivity, symmetry and transitivity of fuzzy relation given in programme set $U$, and determine whether it is a fuzzy correlativity.

(2) Under the premise of fuzzy correlativity, discuss the related category of $U$ divided by $\alpha$-cut set from different levels of $\alpha \in[0,1]$. It should be noted that the necessary and sufficient condition of two projects $u, v$ (namely two elements in fuzzy correlativity) belonging to the same sub-programme $A_{i}^{(\alpha)}$ is $R(u, v) \geq \alpha$. Then analyze the clustering of project set $U$ divided by different levels of $\alpha$ and choose the suitable one.

In order to demonstrate this method, let's assume here programme set $U=\left\{u_{1}, u_{2}, u_{3}, u_{4}, u_{5}\right\}$ consists of 5 projects, the fuzzy relation in $U$ is given by the following fuzzy matrix: 


$$
R=\left(\begin{array}{lcccc}
1 & 0.48 & 0.62 & 0.41 & 0.47 \\
0.48 & 1 & 0.48 & 0.41 & 0.47 \\
0.62 & 0.48 & 1 & 0.41 & 0.47 \\
0.41 & 0.41 & 0.41 & 1 & 0.41 \\
0.47 & 0.47 & 0.47 & 0.41 & 1
\end{array}\right)
$$

Step 1: It can be directly seen from the fuzzy matrix above that fuzzy relation $R$ is reflexive and symmetrical, and $R^{2}=R$ can be given through direct calculation, so $R^{2} \subseteq R$ is tenable and $R$ is transitive, that is, $R$ is the fuzzy correlativity $R$ of project set $U$.

Step 2: $\alpha$-cut set $R_{0 \text { o }}$ of $R_{0}$ is the fuzzy correlativity of $U$, and $R_{0 \%}$ is used to divide set $U$. The different divisions of set $U$ according to various levels of $\alpha(\alpha \in[0,1])$ are as follows:

(1)When $0 \leq \alpha \leq 0.41$, any $u_{i}, u_{j} \in U$ gets $\underset{0}{R}\left(u_{i}, u_{j}\right) \geq \alpha$, so all elements in $U$ cluster into the same category: $\left\{u_{1}, u_{2}, u_{3}, u_{4}, u_{5}\right\}$. That is, there is only one sub-programme.

(2) When $0.41<\alpha \leq 0.47$ and $i, j=1,2,3,5, R_{0}^{R}\left(u_{i}, u_{j}\right) \geq 0.47$, so $u_{1}, u_{2}, u_{3}, u_{5}$ cluster into the same category. At this time, $R\left({ }_{0}\left(u_{4}, u_{i}\right)=0.41\right.$, so $u_{4}$ is divided into a category separately, and project set $U$ is divided into 2 sub-programmes: $\left\{u_{1}, u_{2}, u_{3}, u_{5}\right\},\left\{u_{4}\right\}$.

(3)When $0.47<\alpha \leq 0.48$, project set $U$ is divided into 3 sub-programmes: $\left\{u_{1}, u_{2}, u_{3}\right\},\left\{u_{4}\right\},\left\{u_{5}\right\}$.

(4)When $0.48<\alpha \leq 0.62, u_{1}, u_{3}$ belong to the same category because $R_{0}\left(u_{1}, u_{3}\right)=0.62 \geq \alpha$, so project set $U$ is divided into 4 sub-programmes: $\left\{u_{1}, u_{3}\right\},\left\{u_{2}\right\},\left\{u_{4}\right\},\left\{u_{5}\right\}$.

(5) When $0.62<\alpha \leq 1$, each element in $U$ is merely related to itself, so project set $U$ is divided into 5 sub-programmes: $\left\{u_{1}\right\},\left\{u_{2}\right\},\left\{u_{3}\right\},\left\{u_{4}\right\},\left\{u_{5}\right\}$.

The diagram of fuzzy dynamic clustering above is shown as follows (Fig.2):

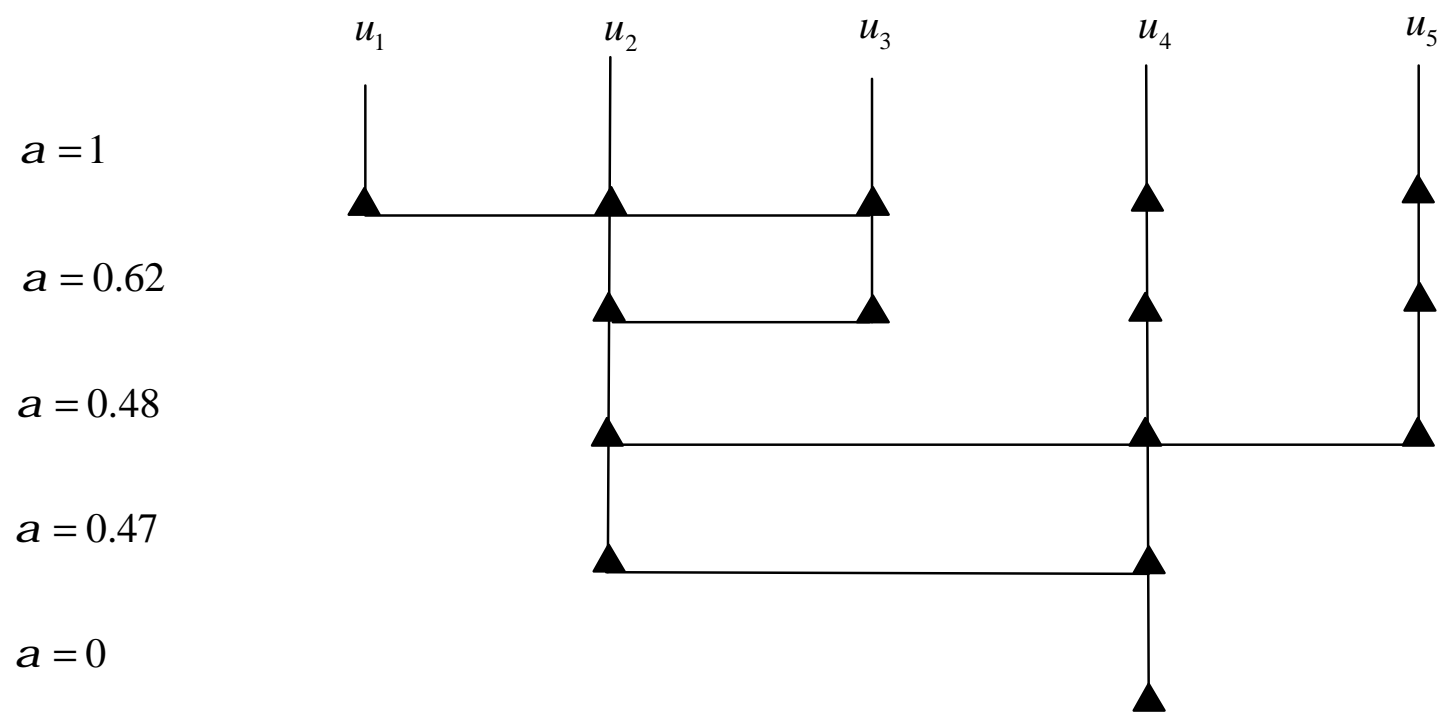

\section{Fig.2 Dynamic clustering}

The fuzzy correlativity between every two projects of programme is the foundation of fuzzy clustering, and it is an important work for programme management office to determine fuzzy relation. Programme is dynamic and changeable in life cycle, and reasons causing these changes come from both external environmental factors and internal factors, so determining the fuzzy relation of projects is dynamic, and dividing the sub-programme of programme also varies. Analyzing programme structurally and clustering projects to certain extent can simplify programme management and make management process more targeted.

Sub-programme sorting of programme. After decomposition and clustering, there are sub-programmes in programme. Multiple sub-programmes are distinct in terms of importance, and 
programme management not only is systematic and comprehensive but also stresses focal points so that limited resources can play a biggest role, which involves in the sorting of sub-programmes.

Generally, the sorting of sub-programmes is a problem of evaluating and sequencing system, with multiple targets and judgment bases. If the correctness of sorting is evaluated just by means of appraisers' qualitative analysis and logical judgment, lack of basis of quantitative analysis, it is obviously difficult to do so. Meanwhile, the characteristics of programme also determine that it is difficult to analyze the sorting of sub-programme in the system accurately and quantitatively. If the quantitative analysis is introduced into the qualitative evaluation, and manager's evaluation by comparison between every two projects is considered, a more scientific evaluation result will be probably acquired. In view of these factors, analytical hierarchy process (AHP) is a better choice. (Fig. 3)

The main steps of using AHP to sort sub-programmes are as follows:

(1)Establish a multi-level hierarchical structural model for important indexes (criterions) of sorting sub-programmes.

(2) Compare between every two projects, determine their relative importance degrees based on evaluation scale and establish judgment matrix.

(3) Calculate the eigenvector of the judgment matrix above to determine the relative importance degree of each element.

(4) Ultimately, sort all sub-programmes by synthesizing the calculation of these important degrees.

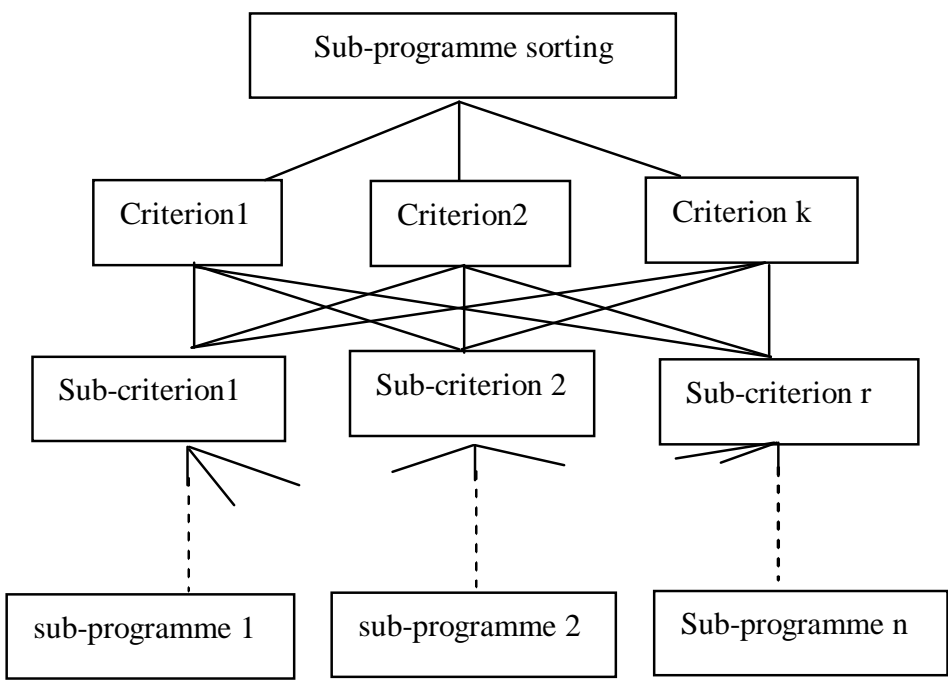

Objective Level

Sorting criterion level

Sorting sub-criterion level

Fig. 3 Structural model of sub-programme sorting by AHP

During the process of sub-programme sorting, it is very important to select the criterions of sorting, and different criterions may lead to various results. And there is no fixed mode to determine these criterions, because programme system is complex structurally and various in property, different organizations are greatly distinct in selecting these criterions, and the same manager also selects diverse criterions at different phases of programme life cycle. In general, the selection of criterions can't be simply summed up as the problem related to benefits, costs and validity, and is often difficult to sort sub-programmes using single hierarchical structure. Looking back on the definition of programme management, it is clear that its ultimate goal is to get the interests that single project management can't acquire. Therefore, thinking of additional interests allows managers to more comprehensively set the criterion level. Interests can't be simply interpreted as flexible ones, such as object of capital, reasonable allocation of resource, orderly flow of information, accumulation and diffusion of knowledge, improvement of congruousness, rapid response of risk as well as improvement of participant's satisfactory degree, and at the same time those difficult to measure must be also stressed. Probably, these interests can't be reflected in financial statement in a short period of time, but they are 
absolutely necessary for successful programme management and positive development of an enterprise.

\section{Conclusion}

At the top of an organization strategic management is taken seriously while at the executive level project management is widely applied. However, proper strategy is often difficult to carry out successfully, because there is always a separation between strategic and implementation levels. Strategy, as an orientation, a planning and a mode of an enterprise, is a process of development, and the uncertainty of environment, unpredictability of future, complexity of system as well as non-uniformity of development makes the formation of strategy be a process of gradual evolution and accumulation. In a way, strategic management is macroscopic and changeable and is a process of gradually approximating to exactness, while project management used to achieve the strategy is required to get a correct result under certain constraint condition. The internal inconsistency between these two management processes is reflected more obviously in the process of multi-project operation. Project managers compete with each other for success in project management so that it is difficult for an enterprise to make a concerted effort generally, and the individuals seeking local optimization can't express them as the overall advantage of the enterprise, on the contrary, they easily lead to the failure of strategic implementation.

Programme management is aimed at resolving the internal contradiction between strategic management and project management, and programme is built under the strategic guidance of an organization to establish a bridge between strategy and project implementation. Programme itself is a system which consists of related, interactional elements (projects). Further, it has integrity, that is, the interrelation and interaction of projects composing programme need be subordinated to the overall objective and function of the system. Of course, all sub-programme (project) activities are conducted grounded in the overall objective and function, and these activities take shape a systematic organic conduct. In the programme system as a whole, while all projects are not always perfect, they can coordinate with each other and integrate into a system with satisfactory function. On the contrary, even if each project is successful, but programme system as a whole has no good function, it can't be called a system with satisfactory function, namely, successful programme management.

Programme system consists in certain environment, and exchanges material, energy and information with it. The changes of environment inevitably trigger adjustment of strategy as well as variations of objective, function and structure of programme system. If an enterprise hopes to keep up with environmental changes, programme management must adapt to these changes, and the adaptation shall be reflected in each process of programme life cycle. Therefore, there are essential differences between life cycles of programme and project, and the tasks of planning, organizing, developing and evaluating in programme life cycle are largely different from those of project management. Programme management is mainly completed by programme management office which, equivalent to a central processing unit, accomplishes a series of coordination and control tasks.

For the programme system varies with changes of environment and time, in order to ensure the effectiveness and efficiency of programme management, programme must be managed dynamically. Meanwhile, identifying, clustering and sorting programme dynamically ensure that the system can adjust its structure and function with changes of environment, and programme continuously gets additional interests that the system outputs in order through these methods of dynamic management.

\section{References}

[1] Ferns DC: Developments in programme management. International Journal of Project Management, Vol. 9 (1991), p. 148-156.

[2] Pellegrinelli S: Programme management: organising project based change. International Journal of Project Management, Vol. 15 (1997), p. 141-149. 
[3] Lycett M. Rassau A. Danson J: Programme management: a critical review. International Journal of Project Management, Vol. 22 (2004), p. 289-299.

[4] PMI (Project Management Institute): Guide to the project management body of knowledge. Upper Darby, PA: PMI. ( 2000).

[5] APM (Association for Project Management): Body of Knowledge. APM: High Wycombe, UK, (2000).

[6] OGC(Office of Government Commerce): Managing successful programmes. OGC: The Stationery Office, UK, (2007).

[7] Meier, S.R: Best project management and systems engineering practices in the preacquisition phase for federal intelligence and defense agencies. Project Management Journal, Vol. 39 (2008 ), p.59-71.

[8] P2M: A Guidebook of Project and Program Management for Enterprise Innovation. Project Management Professionals Certification Centre (PMCC), Tokyo, Japan, (2008).

[9] Pellegrinelli S, Partington D, Hemingway C, Mohdzain Z, Shah M: The importance of context in programme management: an empirical review of programme practices. International Journal of Project Management, Vol. 25 (2007), p. 41-55.

[10] Reiss G, Anthony M, Chapman J, Leigh G, Payne A, Rayner P: Gower handbook of programme management. Gower Publications, UK, (2006). 